\title{
The relationship between urban environment and the inflammatory bowel diseases: a systematic review and meta-analysis
}

Ing Shian Soon ${ }^{1,2+}$, Natalie A Molodecky ${ }^{1,2+}$, Doreen M Rabi ${ }^{1,2}$, William A Ghali ${ }^{1,2}$, Herman W Barkema ${ }^{2,3}$ and Gilaad G Kaplan ${ }^{1,2,4^{*}}$

\begin{abstract}
Background: The objective of this study was to conduct a systematic review with meta-analysis of studies assessing the association between living in an urban environment and the development of the Crohn's disease (CD) or ulcerative colitis (UC).

Methods: A systematic literature search of MEDLINE (1950-Oct. 2009) and EMBASE (1980-Oct. 2009) was conducted to identify studies investigating the relationship between urban environment and IBD. Cohort and case-control studies were analyzed using incidence rate ratio (IRR) or odds ratio (OR) with $95 \%$ confidence intervals (Cls), respectively. Stratified and sensitivity analyses were performed to explore heterogeneity between studies and assess effects of study quality.

Results: The search strategy retrieved 6940 unique citations and 40 studies were selected for inclusion. Of these, 25 investigated the relationship between urban environment and UC and 30 investigated this relationship with CD. Included in our analysis were 7 case-control UC studies, 9 case-control CD studies, 18 cohort UC studies and 21 cohort CD studies. Based on a random effects model, the pooled IRRs for urban compared to rural environment for UC and CD studies were $1.17(1.03,1.32)$ and $1.42(1.26,1.60)$, respectively. These associations persisted across multiple stratified and sensitivity analyses exploring clinical and study quality factors. Heterogeneity was observed in the cohort studies for both UC and CD, whereas statistically significant heterogeneity was not observed for the case-control studies.
\end{abstract}

Conclusions: A positive association between urban environment and both CD and UC was found. Heterogeneity may be explained by differences in study design and quality factors.

Keywords: Inflammatory bowel disease, Urban population, Risk factors

\section{Background}

The etiology of the inflammatory bowel diseases (IBD) has been extensively studied [1], however, the environmental determinants of disease pathogenesis are not fully understood $[2,3]$. IBD is widely believed to be associated with industrialization of nations. This hypothesis is supported by the significant geographic variation in

\footnotetext{
*Correspondence: ggkaplan@ucalgary.ca

${ }^{\dagger}$ Equal contributors

'Departments of Medicine, University of Calgary, Alberta, Canada

${ }^{2}$ Department of Community Health Sciences, University of Calgary, Alberta,

Canada

Full list of author information is available at the end of the article
}

IBD with the highest incidence rate of IBD in North America and Europe [4]. Migrant studies have demonstrated that immigrants, and particularly their offspring, from low prevalent regions acquire a similar risk of IBD as the local population [5]. Furthermore, the incidence of IBD is steadily rising in several developing nations as they have become industrialized [6,7]. Within a country the incidence of IBD has been proposed to be higher in urban versus rural areas $[8,9]$.

Although numerous studies have investigated the association between urban environment and IBD, findings remain inconsistent. An urban association has been considered as far back as 1963, when Acheson and Nefzger

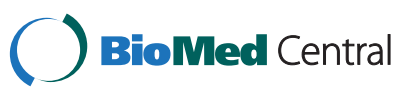


suggested a positive relationship between urban areas and ulcerative colitis (UC) [10]. Many observational studies have subsequently shown an increase in UC and Crohn's disease (CD) incidence in more densely populated areas [8,11-15]. Numerous studies, however, have failed to find an association between urban exposure and IBD $[4,16]$, while others have shown an inverse association [17]. Establishing whether the risk of IBD is greater in urban environments is important because environmental exposures in urban societies are significantly different than those in rural areas. This information may direct research initiatives on specific environmental risk factors of IBD and establish distribution of IBD burden in society.

A systematic analysis of the association between living in an urban environment and IBD has yet to be conducted. Thus, we performed a systematic review and meta-analysis of all case-control and cohort studies that explored the association between residing in an urban region and IBD in order to determine whether the risk of $\mathrm{CD}$ and/or UC was increased in urban as compared to rural areas.

\section{Methods}

\section{Search strategy}

We conducted a systematic literature search using a predetermined protocol and in accordance with the quality of reporting meta-analyses of observational studies (MOOSE) [18]. We searched two computer-stored databases, Medline (1950-present) and Embase (Excerpta Medica Database; 1980-present) for studies describing the association between urban environment and IBD as of October 2009. The search strategy for Medline and Embase was conducted based on three themes. The first theme, the outcome measure, combined the exploded version of Medical Subject Headings (MESH) "inflammatory bowel disease" or "Colitis, Ulcerative" or "Crohn Disease". The second theme, the exposure, combined the exploded version of MESH headings "urban population" or "urban health" or "rural population" or "rural health" or "geography". The third theme combined exploded versions of MESH headings "risk factors" or "risk assessment" or "epidemiology" or "demography". All the keywords were used to search the titles and abstracts. The search was not limited by language or human subjects to ensure capture of all appropriate papers. Abstracts from the American College of Gastroenterology for 2006, 2007, and 2008, and the American Gastroenterological Association for 2006 and 2007 were reviewed. The reference lists of relevant articles were also reviewed.

\section{Selection criteria}

Two reviewers (N.M. and I.S.) identified articles eligible for further review by performing an initial screen of identified abstracts and titles. Articles were eliminated in this initial screen if they were not observational or did not either investigate environmental risk factors for IBD in a case-control study or investigate epidemiology of IBD using incident cases. Studies that did not report original data and duplicated publications were also excluded. Full-text of the remaining articles were retrieved and systematically reviewed. Articles were considered for inclusion in the second screening if they reported a measure of association between urban environment and UC and/or CD. In both study designs, UC and $\mathrm{CD}$ were required to be reported separately for inclusion into the systematic review. Studies that did not report adequate information to calculate incidence rate ratio (IRR) or odds ratio (OR) with $95 \%$ confidence interval (CI) were excluded. Disagreement between reviewers was resolved by consensus with third party experts (DR and GK).

\section{Data extraction}

The outcome variable of interest was defined as the presence of $\mathrm{UC}$ and/or $\mathrm{CD}$. The exposure variable of interest was residing in an urban versus rural environment. Urban and rural populations were not consistently defined across all studies. Several studies ( $\mathrm{n}=10$ for UC; $\mathrm{n}=11$ for $C D$ ) did not define an urban and/or rural environment [12,13,16,17,19-31]. The studies that defined this exposure used definitions that varied and some papers stratified by multiple levels of exposure (e.g. urban, semi-urban, and rural) [24,32-36]. A priori we identified studies that defined urban as a population greater than $10,000[37,38]$. Secondary variables extracted from the manuscripts included: study design (i.e. case-control or cohort); country of origin; publication year; timing of exposure; source of controls for case-control studies; and information on key indicators of study quality, using MOOSE [18].

We extracted reported OR and IRR with 95\% (CIs) or data enabling the calculation of these association measures. Both adjusted and unadjusted values were extracted; though, when available, the adjusted estimates were used.

\section{Statistical analysis}

Meta-analyses were initially conducted by combining cohort and case-control studies using IRRs, defined as the incidence rate of IBD in urban versus rural populations. Given the low prevalence of IBD, the OR would approximate the IRR under the rare disease assumption. Case-control and cohort studies were then analyzed separately using different measures of association. The IRR was used as measure of association for cohort studies and OR was used for case-control studies. The Test of Heterogeneity was performed using a Q statistic (5\% level) and random effects models were used because of the presence of heterogeneity between studies. 
Stratified analyses were performed to explore factors that may explain heterogeneity between studies. Publication year was a priori stratified into three year categories: 1962-1988; 1989-1998; and 1999-2009. Similarly, stratified analyses and meta-regression were performed based on study design (i.e. case-control or cohort study), region of publication, timing of exposure, and source of controls in case-control studies. Sensitivity analyses were performed to exclude studies that did not include a definition of urban/rural region. Further sensitivity analysis was conducted on studies that used $>10,000$ people as a definition of urban environment [37,38]. Papers that stratified by multiple levels of exposure (e.g. urban, semiurban, and rural) were analyzed as urban versus rural. The possibility of publication bias was assessed using the Begg tests.

\section{Results}

\section{Literature search}

The search strategy retrieved 6940 unique citations: 2964 from Medline and 3976 from Embase. Of these, 6434 citations were excluded after the first screening based on titles and abstracts, leaving 506 articles for fulltext review (Figure 1). The observed agreement between reviewers for eligibility of articles was $97 \%$, corresponding to a kappa statistic of 0.77 . Upon full text review of 506 articles, 466 were excluded (see Figure 1 for rationale of exclusions), leaving 40 studies for final inclusion in the systematic review and meta-analysis. Of these 40 studies, 25 investigated the relationship between urban environment and UC and 30 investigated this relationship with $\mathrm{CD}$. Included in our analysis were 7 case-control UC studies, 9 case-control CD studies, 18 cohort UC studies, and 21 cohort CD studies.

\section{Demographic and study quality characteristics}

Characteristics of the 18 cohort studies for UC are shown in Table 1 [19-21,23,24,32-35,39-45]. The reported incidence rate ranged from 0.97 to 15.6 per $100,000 /$ year. A definition for urban and/or rural environment was provided for 13 cohort studies. Characteristics of the 7 selected case-control studies for UC are shown in Table $2[8,12,17,26-28,46]$. Two of the studies had definitions for urban and/or rural environment. Characteristics of the 21 selected cohort studies for $\mathrm{CD}$ are shown in Tables 1 [14,15,22,23,25,30,31,36,39-43,45,47-52]. The reported incidence rate of $\mathrm{CD}$ ranged from 0.51 to 15.6 per 100,000/year. A definition for urban environment was reported in 16 studies. Characteristics of the nine selected case-control studies for CD are shown in Table 2 $[8,13,16,17,27,29,46,53]$. The studies were based in North America, Australia, Asia and Europe. The association between urban environment and IBD was not the primary outcome of interest in any of the cohort or case-control studies.

\section{Urban/rural environment and IBD}

The pooled crude IRR for the 25 UC studies was 1.17 (1.03, 1.32) (Figure 2A). For the 18 cohort studies, the pooled crude IRR was $1.19(1.03,1.36)$ (Figure 2B). In 13 of the studies, a positive association between UC and urban environment was found, 7 of which were statistically

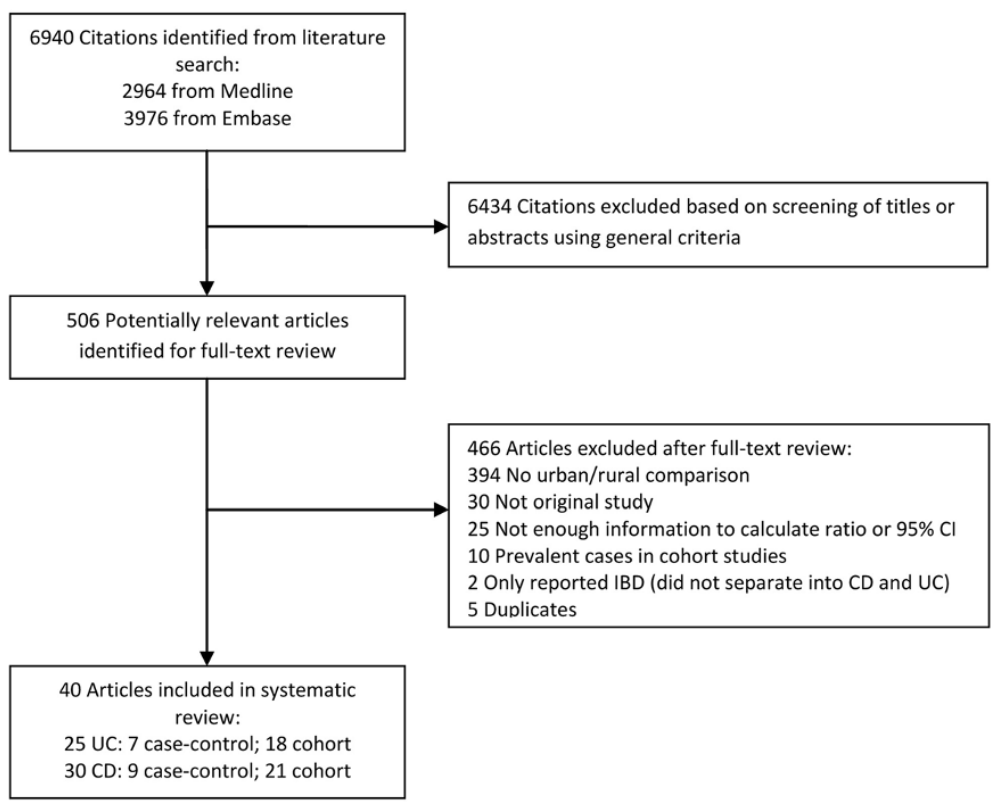

Figure 1 Literature search results. 
Table 1 Characteristics of cohort studies for ulcerative colitis and Crohn's disease studies

\begin{tabular}{|c|c|c|c|c|c|c|c|c|c|c|}
\hline \multicolumn{5}{|c|}{ Study characteristics and demographics } & \multicolumn{6}{|c|}{ Study Quality Characteristics } \\
\hline Author (year) & Country & $\begin{array}{l}\text { Study } \\
\text { period }\end{array}$ & $\begin{array}{l}\text { Number } \\
\text { of cases }\end{array}$ & $\begin{array}{l}\text { Incidence of UC } \\
\text { (per 100,000) }\end{array}$ & $\begin{array}{l}\text { Methods } \\
\text { of diagnosis } \\
\text { defined }\end{array}$ & $\begin{array}{l}\text { Diagnosis } \\
\text { based on } \\
\text { recognized } \\
\text { criteria }\end{array}$ & $\begin{array}{l}\text { Urban/rural } \\
\text { defined }\end{array}$ & $\begin{array}{l}\text { Urban } \\
\text { population } \\
>10,000\end{array}$ & $\begin{array}{l}\text { Time of } \\
\text { exposure }\end{array}$ & $\begin{array}{l}\text { Multiple } \\
\text { levels of } \\
\text { exposure }\end{array}$ \\
\hline \multicolumn{11}{|l|}{ Ulcerative Colitis } \\
\hline Mate-Jimerez 1994[39] & Spain & $1981-88$ & 111 & 3.16 & Yes & Yes & Yes & Yes & At diagnosis & No \\
\hline Ekbom 1991[40] & Sweden & $1965-83$ & 2509 & 10.5 & Yes & Yes & Yes & No & At diagnosis & No \\
\hline Linden 1971[19] & Finland & 1967 & 223 & 4.76 & No & N/A & No & No & At diagnosis & No \\
\hline Probert 1992[32] & UK & $1972-80$ & 192 & 5.33 & Yes & Yes & Yes & No & At diagnosis & Yes \\
\hline Probert 1992[32] & UK & 1981-89 & 211 & 7.29 & Yes & Yes & Yes & No & At diagnosis & Yes \\
\hline Niv 1990[33] & Israel & $1967-86$ & 43 & 2.33 & Yes & No & Yes & No & At diagnosis & Yes \\
\hline Kildebo 1990[22] & Norway & 1983-86 & 179 & 13.2 & Yes & Yes & No & No & At diagnosis & No \\
\hline Gheorghe 2004[23] & Romania & $2002-03$ & 163 & 0.97 & Yes & Yes & No & No & At diagnosis & No \\
\hline Sincic 2006[41] & Croatia & 2000-04 & 70 & 4.6 & Yes & Yes & Yes & No & At diagnosis & No \\
\hline Tsianos 1994[24] & Greece & 1982-91 & 61 & 4.18 & Yes & Yes & No & No & At diagnosis & Yes \\
\hline Ladas 2005[34] & Greece & 1990-94 & 56 & 10.6 & Yes & Yes & Yes & Yes & At diagnosis & Yes \\
\hline Moller 1971[20] & Finland & $1956-67$ & 505 & 1.07 & Yes & Yes & No & No & At diagnosis & No \\
\hline Blanchard 2001[42] & Canada & $1987-96$ & 1763 & 15.6 & Yes & Yes & Yes & No & At diagnosis & No \\
\hline Green 2006[15] & Canada & 1990-01 & N/A & 13.5 & No & N/A & Yes & No & At diagnosis & No \\
\hline Lakatos 2003[43] & Hungary & 1977-01 & 560 & 5.89 & Yes & Yes & Yes & No & At diagnosis & No \\
\hline Manousos 1996[44] & Greece & 1990-94 & 117 & 8.9 & Yes & Yes & Yes & No & At diagnosis & No \\
\hline Wigley 1962[35] & New Zealand & $\mathrm{N} / \mathrm{A}$ & 132 & $\mathrm{~N} / \mathrm{A}$ & Yes & No & Yes & Yes & At diagnosis & Yes \\
\hline Latour 1996[45] & Belgium & 1993-94 & 36 & 3.5 & Yes & Yes & Yes & No & At diagnosis & No \\
\hline \multicolumn{11}{|l|}{ Crohn's Disease } \\
\hline Kyle 1971[47] & UK & $1955-69$ & 166 & 1.98 & Yes & Yes & Yes & No & At diagnosis & No \\
\hline Jayanthi 1992[48] & UK & $1972-80$ & 161 & 2.89 & Yes & Yes & Yes & Yes & At diagnosis & No \\
\hline Jayanthi 1992[48] & UK & 1981-89 & 233 & 4.48 & Yes & Yes & Yes & Yes & At diagnosis & No \\
\hline Mate-Jimerez 1994[39] & Spain & $1981-88$ & 57 & 1.61 & Yes & Yes & Yes & Yes & At diagnosis & No \\
\hline Ekbom 1991[40] & Sweden & $1965-83$ & 1469 & 6.09 & Yes & Yes & Yes & No & At diagnosis & No \\
\hline Shivananda 1987[36] & Netherlands & 1979-83 & 54 & 3.90 & Yes & Yes & Yes & No & At diagnosis & Yes \\
\hline Kildebo 1989[22] & Norway & $1983-86$ & 82 & 5.85 & Yes & Yes & No & No & At diagnosis & No \\
\hline Kyle 1992[49] & Scotland & $1955-88$ & 856 & 5.65 & Yes & Yes & Yes & No & At diagnosis & No \\
\hline Manousos 1996[44] & Greece & 1990-94 & 37 & 3.00 & Yes & Yes & Yes & Yes & At diagnosis & No \\
\hline Gheorghe 2004[23] & Romania & 2002-03 & 85 & 0.51 & Yes & Yes & No & No & At diagnosis & No \\
\hline
\end{tabular}


Table 1 Characteristics of cohort studies for ulcerative colitis and Crohn's disease studies (Continued)

\begin{tabular}{|c|c|c|c|c|c|c|c|c|c|c|}
\hline Sincic 2006[41] & Croatia & $2000-04$ & 100 & 6.50 & Yes & Yes & Yes & No & At diagnosis & No \\
\hline Phavichitr 2003[25] & Australia & 1971-01 & 351 & 1.02 & Yes & Yes & No & No & At diagnosis & No \\
\hline Moum 1996[50] & Norway & 1990-93 & 225 & 5.86 & Yes & Yes & Yes & No & At diagnosis & No \\
\hline Blanchard 2001[42] & Canada & 1987-96 & 1765 & 15.6 & Yes & Yes & Yes & No & At diagnosis & No \\
\hline Green 2006[15] & Canada & 1990-01 & N/A & 14.8 & No & N/A & Yes & No & At diagnosis & No \\
\hline Lakatos 2003[43] & Hungary & 1977-01 & 212 & 2.23 & Yes & Yes & Yes & No & At diagnosis & No \\
\hline Nyhlin 1986[51] & Sweden & $1974-81$ & 253 & 4.90 & Yes & Yes & Yes & No & At diagnosis & No \\
\hline Ruiz Ochoa 1984[30] & Spain & 1976-83 & 152 & 0.80 & Yes & Yes & No & No & At diagnosis & No \\
\hline Sedlack 1980[31] & USA & 1935-75 & 103 & 4.20 & Yes & No & No & No & At diagnosis & No \\
\hline Brandes 1983[52] & Germany & 1964-75 & 97 & 3.00 & Yes & No & Yes & No & At diagnosis & No \\
\hline Latour 1996[45] & Belgium & 1993-94 & 56 & 5.50 & Yes & Yes & Yes & No & At diagnosis & No \\
\hline
\end{tabular}


Table 2 Characteristics of case-control studies for ulcerative colitis and Crohn's disease studies

\begin{tabular}{|c|c|c|c|c|c|c|c|c|c|c|c|}
\hline \multicolumn{4}{|c|}{ Study characteristics and demographics } & \multicolumn{8}{|c|}{ Study quality characteristics } \\
\hline Author (year) & Country & $\begin{array}{l}\text { No. of } \\
\text { cases }\end{array}$ & $\begin{array}{l}\text { No. of } \\
\text { controls }\end{array}$ & Source of controls & $\begin{array}{l}\text { Controls } \\
\text { matched for: }\end{array}$ & $\begin{array}{l}\text { Methods of } \\
\text { diagnosis } \\
\text { defined }\end{array}$ & $\begin{array}{l}\text { Diagnosis } \\
\text { based on } \\
\text { recognized } \\
\text { criteria }\end{array}$ & $\begin{array}{l}\text { Urban/rural } \\
\text { defined }\end{array}$ & $\begin{array}{l}\text { Urban } \\
\text { population } \\
>10,000\end{array}$ & Time of exposure & $\begin{array}{l}\text { Multiple } \\
\text { levels of } \\
\text { exposure }\end{array}$ \\
\hline \multicolumn{12}{|l|}{ Ulcerative Colitis } \\
\hline Parrello 1997[26] & Italy & 509 & 657 & $\begin{array}{l}\text { Attending orthopedic } \\
\text { and surgical clinics }\end{array}$ & $\begin{array}{l}\text { Sex, age, year of } \\
\text { diagnosis }\end{array}$ & Yes & Yes & No & No & Time of data collection & No \\
\hline Feeney 2002[17] & UK & 137 & 137 & Functional Gl Disorders & Sex, age & Yes & Yes & No & No & Childhood (age 0-5) & No \\
\hline Bernstein 2007[27] & Canada & 137 & 310 & $\begin{array}{l}\text { Manitoba Health } \\
\text { Population Registry }\end{array}$ & Sex, age & No & N/A & No & No & N/A & No \\
\hline Jiang 2007[28] & China & 177 & 177 & Neighbours or colleagues & Sex, age & Yes & Yes & No & No & Childhood & No \\
\hline Radon 2007[54] & Germany & 304 & 1481 & Strabismus surgery & Age & No & N/A & No & No & Time of data collection & No \\
\hline $\begin{array}{l}\text { Martinez Salmeron } \\
\text { 1994[46] }\end{array}$ & Spain & 63 & 63 & Hospital & Sex, age & Yes & Yes & Yes & No & Time of data collection & No \\
\hline Ekbom 1990[8] & Sweden & 164 & 328 & $\begin{array}{l}\text { Live births between } \\
\text { 1924-1957 in Uppsala } \\
\text { County }\end{array}$ & $\begin{array}{l}\text { Date of birth, sex, } \\
\text { and maternal age } \\
\text { or parity }\end{array}$ & Yes & Yes & Yes & No & Time of birth & No \\
\hline \multicolumn{12}{|l|}{ Crohn's Disease } \\
\hline Feeney 2002[17] & UK & 139 & 139 & Functional Gl disorders & Sex, age & Yes & Yes & No & No & Childhood (age 0-5) & No \\
\hline Bernstein 2007[27] & Canada & 235 & 310 & $\begin{array}{l}\text { Manitoba Health } \\
\text { Population Registry }\end{array}$ & Sex, age & No & N/A & No & No & N/A & No \\
\hline Ponsonby 2009[53] & Australia & 278 & 998321 & $\begin{array}{l}\text { Live births from } \\
\text { 1983-1998 in } \\
\text { Victoria }\end{array}$ & Age & Yes & No & Yes & No & Childhood (age 0-6) & No \\
\hline Malekzadeh 2009[16] & Iran & 196 & 207 & $\begin{array}{l}\text { IBS treated by an expert } \\
\text { gastroenterologist }\end{array}$ & Age & Yes & Yes & No & No & $\begin{array}{l}\text { Childhood } \\
\text { (before } 16^{\text {th }} \text { birthday) }\end{array}$ & No \\
\hline Radon 2007[54] & Germany & 444 & 1481 & Strabismus surgery & Age & No & N/A & No & No & Time of data collection & No \\
\hline Thompson 1998[29] & England, Wales & 291 & 1682 & Same GP & Sex, age & No & N/A & No & No & N/A & No \\
\hline Wurzelmann 1994[13] & United States & 322 & 262 & Closest neighbour & Sex, age, race & No & N/A & No & No & Childhood (age 0-5) & Yes \\
\hline $\begin{array}{l}\text { Martinez Salmeron } \\
\text { 1994[46] }\end{array}$ & Spain & 30 & 30 & Hospital & Sex, age & Yes & Yes & Yes & No & Time of data collection & No \\
\hline Ekbom 1990[8] & Sweden & 93 & 186 & $\begin{array}{l}\text { Live births between } \\
\text { 1924-1957 in Uppsala } \\
\text { County }\end{array}$ & $\begin{array}{l}\text { Date of birth, sex, } \\
\text { and maternal age } \\
\text { or parity }\end{array}$ & Yes & Yes & Yes & No & Time of birth & No \\
\hline
\end{tabular}




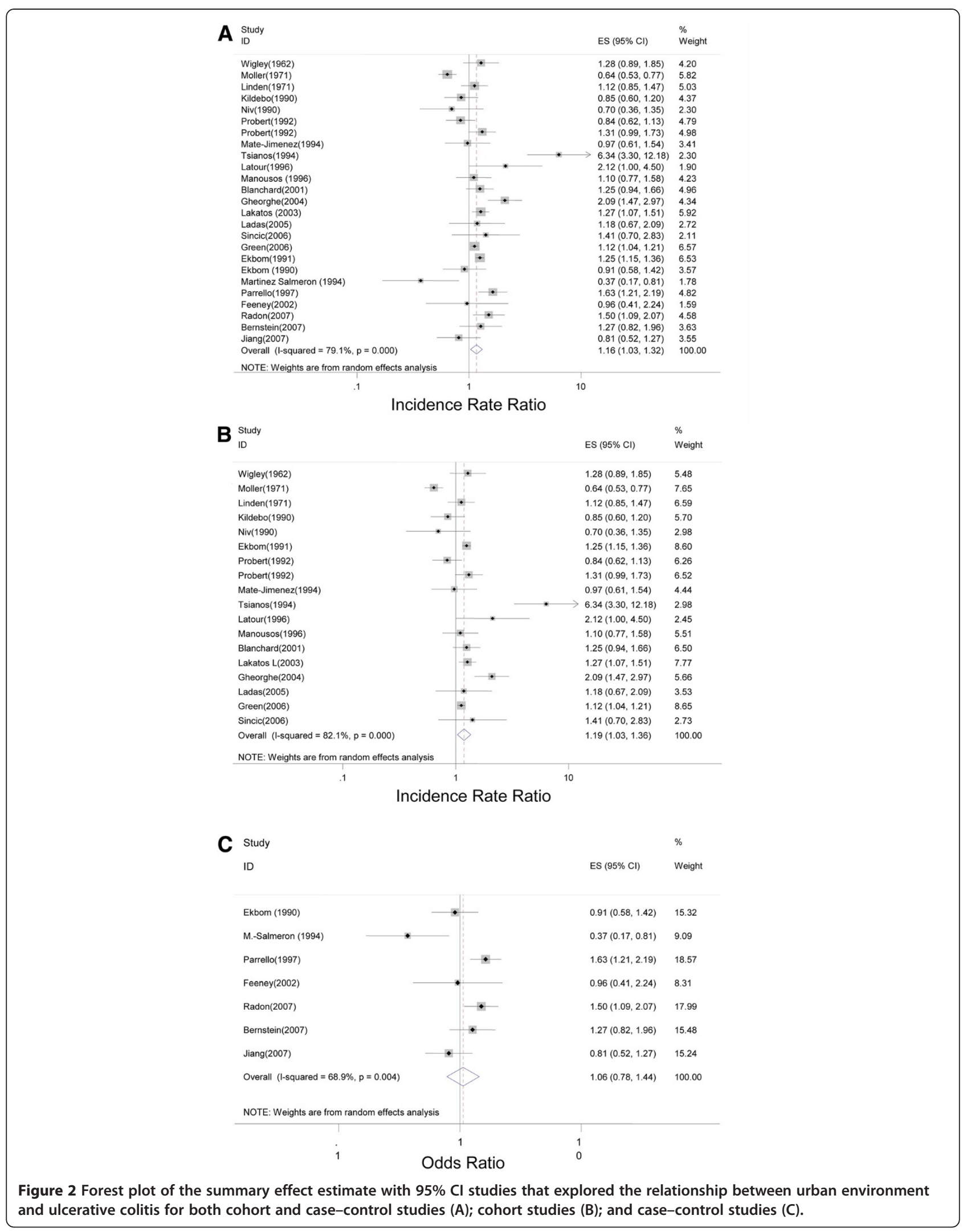



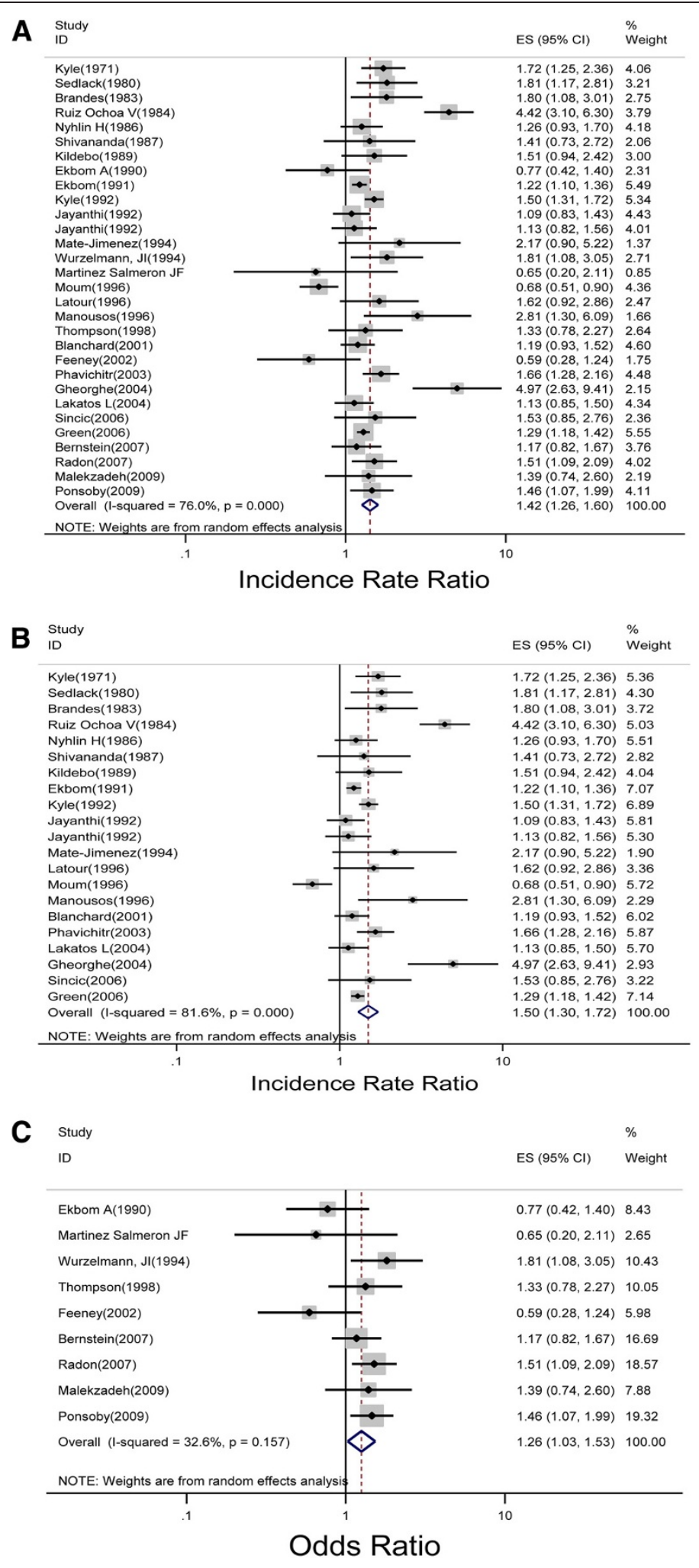

Figure 3 Forest plot of the summary effect estimate with $95 \% \mathrm{Cl}$ studies that explored the relationship between urban environment and Crohn's disease for both cohort and case-control studies (A); cohort studies (B); and case-control studies (C). 
Table 3 Sensitivity and stratified analyses of pooled relative risk for cohort studies

\begin{tabular}{|c|c|c|c|c|c|c|c|c|c|c|c|c|}
\hline & \multicolumn{6}{|c|}{ Ulcerative colitis } & \multicolumn{6}{|c|}{ Crohn's disease } \\
\hline & \multicolumn{4}{|c|}{ Stratified analysis } & \multicolumn{2}{|c|}{ Meta-regression } & \multicolumn{4}{|c|}{ Stratified analysis } & \multicolumn{2}{|c|}{ Meta-regression } \\
\hline & $\begin{array}{l}\text { No. of } \\
\text { studies }\end{array}$ & $\begin{array}{l}\text { No. of } \\
\text { cases }\end{array}$ & $\begin{array}{l}\text { Pooled RR } \\
(95 \% \mathrm{Cl})\end{array}$ & $\begin{array}{l}\text { Heterogeneity } \\
\text { (p-value) }\end{array}$ & Coef. & $\begin{array}{l}P \\
\text { value }\end{array}$ & $\begin{array}{l}\text { No. of } \\
\text { studies }\end{array}$ & $\begin{array}{l}\text { No. of } \\
\text { cases }\end{array}$ & $\begin{array}{l}\text { Pooled RR } \\
(95 \% \mathrm{Cl})\end{array}$ & $\begin{array}{l}\text { Heterogeneity } \\
\text { (p-value) }\end{array}$ & Coef. & $\begin{array}{l}P \\
\text { value }\end{array}$ \\
\hline Crude & 18 & 6901 & $1.19(1.03,1.36)$ & $<.001$ & & & 21 & 6514 & $1.50(1.30,1.72)$ & $<.001$ & & \\
\hline \multicolumn{13}{|c|}{ Definition of urban/rural environment } \\
\hline Urban/rural defined & 13 & 5906 & $1.18(1.09,1.27)$ & .19 & & & 16 & 5741 & $1.28(1.14,1.43)$ & $<.001$ & & \\
\hline Urban defined as $>10,000$ & 3 & 299 & $1.16(0.90,1.50)$ & .65 & & & 4 & 488 & $1.38(0.97,1.97)$ & .072 & & \\
\hline \multicolumn{13}{|l|}{ Year of publication } \\
\hline 1962-1988 & 3 & 860 & $0.96(0.60,1.51)$ & $<.001$ & 0.16 & .30 & 6 & 825 & $1.90(1.27,2.85)$ & $<.001$ & -0.095 & .47 \\
\hline 1989-1998 & 9 & 3459 & $1.23(0.95,1.57)$ & $<.001$ & & & 9 & 3176 & $1.26(1.04,1.53)$ & $<.001$ & & \\
\hline 1999-2009 & 6 & 2612 & $1.30(1.10,1.54)$ & .022 & & & 6 & 2513 & $1.49(1.18,1.87)$ & .001 & & \\
\hline \multicolumn{13}{|l|}{ Region } \\
\hline European countries & 15 & 5036 & $1.21(0.99,1.46)$ & $<.001$ & 0.008 & .98 & 17 & 4295 & $1.55(1.28,1.88)$ & $<.001$ & 0.77 & .75 \\
\hline Non-European countries & 3 & 1895 & $1.13(1.06,1.22)$ & .61 & & & 4 & 2219 & $1.39(1.181 .62)$ & .12 & & \\
\hline \multicolumn{13}{|l|}{ European Countries } \\
\hline Northern & 6 & 3819 & $0.97(0.75,1.27)$ & $<.001$ & -0.26 & .086 & 9 & 3499 & $1.23(1.04,1.45)$ & $<.001$ & 0.23 & .04 \\
\hline Eastern & 2 & 723 & $1.59(0.98,2.59)$ & .013 & & & 2 & 297 & $2.30(0.54,9.82)$ & $<.001$ & & \\
\hline Mediterranean & 6 & 458 & $1.39(0.82,2.36)$ & $<.001$ & & & 4 & 346 & $2.64(1.50,4.62)$ & .02 & & \\
\hline Western & 1 & 36 & $2.12(1.00,4.50)$ & NA & & & 2 & 153 & $1.72(1.17,2.51)$ & .79 & & \\
\hline
\end{tabular}


Table 4 Sensitivity and stratified analyses of pooled odds ratio for case-control studies

\begin{tabular}{|c|c|c|c|c|c|c|c|c|c|c|c|c|c|c|}
\hline & \multicolumn{7}{|c|}{ Ulcerative colitis } & \multicolumn{7}{|c|}{ Crohn's disease } \\
\hline & \multicolumn{5}{|c|}{ Stratified analysis } & \multicolumn{2}{|c|}{ Meta-regression } & \multicolumn{5}{|c|}{ Stratified analysis } & \multicolumn{2}{|c|}{ Meta-regression } \\
\hline & $\begin{array}{l}\text { No. of } \\
\text { studies }\end{array}$ & $\begin{array}{l}\text { No. of } \\
\text { cases }\end{array}$ & $\begin{array}{l}\text { No. of } \\
\text { controls }\end{array}$ & $\begin{array}{l}\text { Pooled OR } \\
(95 \% \mathrm{Cl})\end{array}$ & $\begin{array}{l}\text { Heterogeneity } \\
\text { (p-value) }\end{array}$ & Coef. & $\begin{array}{l}P \\
\text { value }\end{array}$ & $\begin{array}{l}\text { No. of } \\
\text { studies }\end{array}$ & $\begin{array}{l}\text { No. of } \\
\text { cases }\end{array}$ & $\begin{array}{l}\text { No. of } \\
\text { controls }\end{array}$ & $\begin{array}{l}\text { Pooled OR } \\
(95 \% \mathrm{Cl})\end{array}$ & $\begin{array}{l}\text { Heterogeneity } \\
\text { (p-value) }\end{array}$ & Coef. & $\begin{array}{l}P \\
\text { value }\end{array}$ \\
\hline Crude & 7 & 1491 & 3153 & $1.06(0.78,1.45)$ & .004 & & & 9 & 2028 & 1002618 & $1.26(1.03,1.53)$ & .16 & & \\
\hline \multicolumn{15}{|l|}{ Time of exposure } \\
\hline Time of data collection & 4 & 1013 & 2511 & $1.18(0.78,1.80)$ & .006 & -0.32 & .42 & 2 & 474 & 1511 & $1.21(0.58,2.50)$ & .18 & 0.060 & .89 \\
\hline Childhood & 3 & 478 & 642 & $0.87(0.65,1.17)$ & .91 & & & 5 & 1028 & 999115 & $1.18(0.82,1.70)$ & .052 & & \\
\hline $0-6$ years & & & & & & & & 4 & 832 & 998908 & $1.12(0.71,1.77)$ & .026 & 0.16 & .46 \\
\hline$<16$ years & & & & & & & & 1 & 196 & 207 & $1.39(0.74,2.60)$ & NA & & \\
\hline \multicolumn{15}{|l|}{ Source of controls } \\
\hline Population & 2 & 314 & 487 & $1.02(0.66,1.58)$ & .16 & 0.035 & .94 & 3 & 835 & 998893 & $1.40(1.13,1.73)$ & .37 & -0.23 & .32 \\
\hline Clinic/Hospital & 5 & 1177 & 2666 & $1.06(0.70,1.60)$ & .003 & & & 6 & 1193 & 3725 & $1.09(0.79,1.51)$ & .11 & & \\
\hline
\end{tabular}


significant. Heterogeneity across studies was observed (Q statistic, 95.14; $P<.001$ ). For the UC case-control studies, the pooled OR for the association between urban environment and UC was $1.06(0.78,1.45)$ (Figure 2C). Three out of seven studies found a positive association, and two were statistically significant. Heterogeneity was observed across studies ( $Q$ statistic, 19.32; $P=.004$ ). The pooled IRR for the $30 \mathrm{CD}$ studies was $1.42(1.26,1.60)$ (Figure 3A). For the 21 cohort studies, the pooled crude IRR was $1.50(1.30,1.72)$ (Figure 3B). In 20 of the studies, a positive association between $\mathrm{CD}$ and urban environment was found, 10 of which were statistically significant. Heterogeneity across cohort studies was observed (Q statistic, 108.56; $P<.001)$. For the $9 \mathrm{CD}$ case-control studies, the pooled OR for the association between urban environment and CD was $1.26(1.03,1.53)$ (Figure $3 C)$. Six out of the seven studies found a positive association, but only three were statistically significant. Heterogeneity was not observed across studies (Q statistic, 11.88; $P=.157$ ).

\section{Sensitivity and stratified analyses}

After excluding the UC cohort studies that did not define urban and/or rural environment the pooled IRR was $1.18(1.09,1.27)$, which did not differ from the crude pooled IRR (Table 3$)$. The IRR lost significance 1.16 (0.9, 1.5) when we included only studies that defined urban as $>10,000$ people. Only cohort studies published after 1999 demonstrated an association between urban environment and UC (1.30; 95\% CI: 1.10, 1.54). A stratified analysis was similarly performed for region in which the study was based, divided into European and nonEuropean countries. The IRR for Non-European studies was statistically significant with pooled estimate of 1.13 $(1.06,1.22)$. Meta-regression was not statistically significant for year of publication, region of publication and European countries.

For the UC case-control studies, we failed to find a statistically significant association when stratifying by timing of exposure (Table 4). Meta-regression was performed for both timing of exposure and source of controls and no statistically significant associations were found.

After excluding CD cohort studies that did not define urban and/or rural environment, the pooled IRR was $1.28(1.14,1.43)$, which was similar to the crude IRR (Table 3). Restricting the urban definition to $>10,000$ people resulted in a loss of significance with an IRR of $1.38(0.97,1.97)$. The pooled IRRs were statistically significant across all 3 categories of publication year (Table 3). A stratified analysis was similarly performed for region in which the study was based, divided into European and non-European countries. The IRRs for both European and non-European studies were statistically significant with pooled estimates of $1.55(1.28,1.88)$ and $1.39(1.18,1.62)$, respectively. In meta-regression analysis only the European countries variable was statistically significant (Table 3).

For the CD case-control studies, we failed to find a statistically significant association when stratified by timing of exposure (Table 4). Meta-regression was performed for both time of exposure and source of controls and no statistically significant associations were found. The OR for population-based controls was 1.40 (1.13, 1.73) and for hospital/clinic-based controls was 1.09 $(0.79,1.51)$. Meta-regression was performed for both variables and no statistically significant result was found.

\section{Publication bias}

No publication bias was found; the Begg tests were not statistically significant for UC $(\mathrm{z}=-0.42, P=.675)$ or $\mathrm{CD}$ studies $(\mathrm{z}=0.70, P=.487)$.

\section{Discussion}

Urbanization of society is an important risk factor for the development of IBD. This meta-analysis suggests that living in urban environments may increase the risk of developing CD and UC. Though, the strengths of association varied among the 40 studies due to heterogeneity between studies. The association between CD and urban environment persisted across a number of stratified analyses that explored clinical and study quality factors. In contrast, the association between UC and urban environment was weaker and less consistent upon sensitivity analyses. Publication bias was not observed suggesting that the association were likely not an artifact of unpublished studies.

Several theories may explain the increased incidence of IBD in urban societies. The Hygiene Hypothesis proposes that the lack of early childhood exposure to enteric pathogens with improved sanitation in urban cities increases the incidence of IBD [5,55]. The lack of exposure to enteric pathogens may lead to a greater susceptibility to develop an inappropriate immunologic response upon exposure to new antigens (e.g. gastrointestinal infection) later in life [56]. Other environmental risk factors of IBD that are more predominant in urban societies include smoking, lack of helminths exposure, and antibiotic use [57-59]. Additionally, a recent study demonstrated that air pollution in urban cities was associated with IBD in children [60]. Urban occupations such as driving and manufacturing have also been reported as risk factors for IBD [61]. While a cohesive hypothesis that explains the environmental determinants of IBD has not been proven, this meta-analysis supports further research exploring the environmental risk factors of urbanization and IBD.

Heterogeneity was observed in both the CD and UC cohort studies, whereas statistically significant heterogeneity was not observed for the UC and CD case-control studies. This inconsistency was likely due to the large 
overall study population in the cohort studies, leading to an overpowered heterogeneity statistical test. In contrast, the case-control studies were small in total study population. Alternatively, differences in heterogeneity between studies may be explained by the difference in the study design and by the intrinsic biases associated with cohort and case-control studies that explore environmental risk factors of IBD.

When studies were stratified by region the association between UC and urban environment persisted only in non-European studies, whereas the association between $\mathrm{CD}$ and urban environment remained significant in most regions. Regional differences may be due to the fact that studies originated from countries that differed by ethnicity, prevalence of IBD, and rates of IBD susceptibility genes $[62,63]$. Alternatively, the small number of studies in each region made appropriate and meaningful inferences challenging. Furthermore, data was lacking for low prevalent regions (i.e. developing world) and thus we could not explore the urban/rural effect in these regions.

We explored whether the year of publication contributed to the heterogeneity observed between studies. For UC, only publications after 1999 were significant after pooling. This time stratified finding may be due to study design differences in more recent publications or the changing pattern of UC diagnosis. In contrast, the urban/rural relationship persisted across all time strata for $C D$, which suggested a greater strength of association for CD over UC.

The definition of an urban environment was a source of heterogeneity across studies. The studies that clearly defined this exposure included population estimates of the urban and/or rural areas; however, the inconsistency or lack of definitions made study comparisons challenging. We a priori selected the definition of urban as more than 10,000 people because this definition is consistent with census of populations in many Countries (e.g. United Kingdom [37] and Canada [38]). When considering only studies that defined urban as $>10,000$, the association was no longer significant, which was likely due to the small number of studies with this definition ( $\mathrm{n}=2$ for $\mathrm{UC}$ and $\mathrm{n}=4$ for CD). However, this finding may also reflect that the risk associated with urban society may be driven by greater population size (e.g. living in a metropolis) and/or by population density. Ideally, we would have investigated the potential for a dose response effect to explore whether the risk of IBD increased with increasing population sizes. However, few papers stratified their results by multiple levels of exposure; for example, Tsianos [24] and Ladas [34] stratified their analysis into urban, semi-rural, and rural. Future studies of the urban-rural association should explore the importance of a dose response effect, a threshold value of population size, and population density.
Heterogeneity between studies may have occurred due to the biases associated with cohort and case-control studies. For the case-control studies, a selection bias may have influenced the association if cases were selected by a different mechanism than controls. The controls were grouped into population- and hospital/clinic-based selection categories. For CD, only population-based controls demonstrated a significant association with urban environment; in contrast, the urban-rural association was insignificant in both control populations for UC. Additionally, inconsistency in timing of exposure (e.g. defining urban-rural status at time of diagnosis versus childhood) may have contributed to the heterogeneity between casecontrol studies. People in rural settings may have less access to health care leading to under diagnosis of IBD. Although the majority of the case-control studies were matched by age and gender, other potential confounders including socioeconomic status and smoking were often not considered. Finally, studies that used administrative databases to identify IBD patients likely introduced misclassification errors. Interpreting the results of metaanalysis should be cautious because pooling data does not address the intrinsic biases of observational studies.

Limitations in our systematic review should be considered. First, the number of studies included in the stratified analyses was small and may have been underpowered. Second, the quality of studies was not always optimal as was shown with the inconsistent definitions of urban/ rural and time of exposure. Third, the included studies used population estimates as indicators for urban environment; however, other factors that contribute to an urban setting, such as socioeconomic characteristics, were not considered. Finally, due to the nature of observational studies, a temporal relationship could not be determined. Thus, urban environment cannot be conclusively established as a causal factor in IBD.

\section{Conclusions}

In spite of differences in study design and population characteristics, the meta-analysis demonstrated that living in an urban society was positively associated with the development of IBD; though, the consistency and strength of the association was greatest for $\mathrm{CD}$. Additionally, the meta-analysis identified important study limitations and thus, future studies should be properly designed using a standard definition of urban/rural. Furthermore, additional studies are need to evaluate whether the following factors affect the risk of developing IBD: increasing population size (i.e. a dose response effect); a threshold value of population size; the number of people living per unit area (i.e. population density); and the duration and timing of exposure. Finally, the meta-analysis highlights that researchers should continue to explore for environmental differences between urban and rural societies. 


\section{Abbreviations}

CD: Crohn's disease; UC: ulcerative colitis; IRR: incidence rate ratio; OR: odds ratio; IBD: inflammatory bowel disease; MESH: Medical Subject Headings; $\mathrm{Cl}$ : confidence interval.

\section{Competing interests}

None.

\section{Author contributions}

GK. Dr. Kaplan participated in conceiving the study idea, developing the study design, interpreting results, and writing of the manuscript. Dr. Kaplan confirms that he has had full access to all the data in the study and had final responsibility for the decision to submit for publication. Dr. Kaplan has seen and approved the final version of the manuscript and has no relevant conflicts of interest. I S S. Dr. Soon participated in conceiving the study and design, acquisition of data, analysis, interpretation of data, drafting manuscript, and statistical analysis. Dr. Soon has seen and approved the final version of the manuscript and has no relevant conflicts of interest. $N$ M. Ms Molodecky participated in conceiving the study concept and design, acquisition of data, analysis and interpretation of data, drafting manuscript, and statistical analysis. Ms Molodecky has seen and approved the final version of the manuscript and has no conflicts of interest. $D$ R. Dr. Rabi participated in conceiving the study study concept and design, analysis and interpretation of data, and critical revision of the manuscript for important intellectual content. Dr. Rabi has seen and approved the final version of the manuscript. Dr. Rabi has no conflicts of interest. W G. Dr. Ghali participated in analysis and interpretation of data, and critical revision of the manuscript for important intellectual content. Dr. Ghali has seen and approved the final version of the manuscriptand has no conflicts of interest. $H$ B. Dr. Barkema participated in analysis and interpretation of data, and critical revision of the manuscript for important intellectual content. Dr. Barkema has seen and approved the final version of the manuscript, and has no conflicts of interest.

\section{Source of funding}

This research is supported by The Alberta IBD Consortium, which is funded by an AHFMR Interdisciplinary Team Grant. AHFMR is now Alberta Innovates - Health Solutions.

\section{Acknowledgement}

We thank Dr. Brenda Hemmelgarn, Dr. Reg Sauve and Diane Lorenzetti for their helpful comments and suggestions. Additionally, we thank Belle Kaplan for her assistance with this work. Dr. Kaplan is supported through a New Investigator Award from the Canadian Institute of Health Research (CIHR) and a Population Health Investigator Award from the Alberta Heritage Foundation for Medical Research (AHFMR). Natalie Molodecky is supported by an Alberta Heritage Foundation for Medical Research and Crohn's and Colitis Foundation Partnership Studentship. Dr. Soon is supported by the Alberta Children's Hospital Research Institute for Child and Maternal Health and the CIHR Training Program in Genetics, Child Development and Health research fellowship. This research is supported by The Alberta IBD Consortium, which is funded by an AHFMR Interdisciplinary Team Grant AHFMR is now Alberta Innovates - Health Solutions.

\section{Author details}

${ }^{1}$ Departments of Medicine, University of Calgary, Alberta, Canada. ${ }^{2}$ Department of Community Health Sciences, University of Calgary, Alberta, Canada. ${ }^{3}$ Production Animal Health, University of Calgary, Alberta, Canada. ${ }^{4}$ Departments of Medicine and Community Health Sciences, University of Calgary, Teaching Research and Wellness Center, 3280 Hospital Drive NW, 6th Floor, Room 6D17Calgary AB, T2N 4 N1, Alberta, Canada.

Received: 6 April 2012 Accepted: 2 May 2012

Published: 24 May 2012

\section{References}

1. Podolsky DK: Inflammatory Bowel Disease. N Engl J Med 2002, 347:417-429.

2. Mikhailov TA, Furner SE: Breastfeeding and genetic factors in the etiology of inflammatory bowel disease in children. World J Gastroenterol 2009, 15:270-279.
3. Jones DT, Osterman MT, Bewtra M, Lewis JD: Passive smoking and inflammatory bowel disease: a meta-analysis. Am J Gastroenterol 2008, 103:2382-2393.

4. Bernstein CN, Blanchard JF, Rawsthorne P, Wajda A: Epidemiology of Crohn's disease and ulcerative colitis in a central Canadian province: a population-based study. Am J Epidemiol 1999, 149:916-924.

5. Bernstein CN, Shanahan F: Disorders of a modern lifestyle: reconciling the epidemiology of inflammatory bowel diseases. Gut 2008, 57:1185-1191.

6. Zheng JJ, Zhu XS, Huangfu Z, Gao ZX, Guo ZR, Wang Z: Crohn's disease in mainland China: a systematic analysis of 50 years of research. Chin J Dig Dis 2005, 6:175-181.

7. Desai HG, Gupte PA: Increasing incidence of Crohn's disease in India: is it related to improved sanitation? Indian J Gastroenterol 2005, 24:23-24.

8. Ekbom A, Adami HO, Helmick CG, Jonzon A, Zack MM: Perinatal risk factors for inflammatory bowel disease: a case-control study. American Journal of Epidemiology 1990, 132:1111-1119.

9. Gollop JH, Phillips SF, Melton LJ 3rd: Zinsmeister AR: Epidemiologic aspects of Crohn's disease: a population based study in Olmsted County, Minnesota, 1943-1982. Gut 1988, 29:49-56.

10. Farrokhyar F, Swarbrick ET, Irvine EJ: A critical review of epidemiological studies in inflammatory bowel disease.[see comment][erratum appears in Scand J Gastroenterol: Jun;36(6):facing 561]. Scand J Gastroenterol 2001 2001(36):2-15.

11. Klement E, Lysy J, Hoshen M, Avitan M, Goldin E, Israeli E: Childhood hygiene is associated with the risk for inflammatory bowel disease: a population-based study. Am J Gastroenterol 2008, 103:1775-1782.

12. Radon $\mathrm{K}$ : Contact with farm animals in early life and juvenile inflammatory bowel disease: A case-control study. Pediatrics 2007, 120:354-361.

13. Wurzelmann II, Lyles CM, Sandler RS: Childhood infections and the risk of inflammatory bowel disease. Dig Dis Sci 1994, 39:555-560.

14. Manousos ON, Koutroubakis I, Potamianos S, Roussomoustakaki M, Gourtsoyiannis N, Vlachonikolis IG: A prospective epidemiologic study of Crohn's disease in Heraklion, Crete. Incidence over a 5-year period. Scand J Gastroenterol 1996, 31:599-603.

15. Green C, Elliott L, Beaudoin C, Bernstein CN: A population-based ecologic study of inflammatory bowel disease: searching for etiologic clues. American Journal of Epidemiology 2006, 164:615-623. discussion 624-618.

16. Malekzadeh F, Alberti C, Nouraei M, Vahedi H, Zaccaria I, Meinzer U, Nasseri-Moghaddam S, Sotoudehmanesh R, Momenzadeh S, Khaleghnejad R, et al: Crohn's disease and early exposure to domestic refrigeration. PLOS ONE 2009, 4:e4288.

17. Feeney MA, Murphy F, Clegg AJ, Trebble TM, Sharer NM, Snook JA: A case-control study of childhood environmental risk factors for the development of inflammatory bowel disease. Eur J Gastroenterol Hepatol 2002, 14:529-534

18. Stroup DF, Berlin JA, Morton SC, Olkin I, Williamson GD, Rennie D, Moher D, Becker BJ, Sipe TA, Thacker SB: Meta-analysis of observational studies in epidemiology: a proposal for reporting. Meta-analysis Of Observational Studies in Epidemiology (MOOSE) group. Jama 2000, 283:2008-2012.

19. Linden G, Moller C: Ulcerative colitis in Finland. II. One-year incidence in all hospitals. Dis Colon Rectum 1971, 14:264-266.

20. Moller C: Linden G. Ulcerative colitis in Finland. I. Cases treated at central hospitals, 1956-1967. Dis Colon Rectum 1971, 14:259-263.

21. Kildebo S, Nordgaard K, Aronsen O, Breckan R, Burhol PG, Jorde R: The incidence of ulcerative colitis in Northern Norway from 1983 to: The Northern Norwegian Gastroenterology Society. Scand J Gastroenterol 1986, 1990(25):890-896.

22. Kildebo S, Breckan R, Nordgaard K, Burhol PG, Jorde R: The incidence of Crohn's disease in northern Norway from 1983 to: Northern Norway Gastroenterology Society. Scand J Gastroenterol 1986, 1989(24):1265-1270.

23. Gheorghe C, Pascu O, Gheorghe L, lacob R, Dumitru E, Tantau M, Vadan R, Goldis A, Balan G, lacob S, et al: Epidemiology of inflammatory bowe disease in adults who refer to gastroenterology care in Romania: a multicentre study. Eur J Gastroenterol Hepatol 2004, 16:1153-1159.

24. Tsianos EV, Masalas CN, Merkouropoulos M, Dalekos GN, Logan RF: Incidence of inflammatory bowel disease in north west Greece: rarity of Crohn's disease in an area where ulcerative colitis is common. Gut 1994, 35:369-372.

25. Phavichitr N, Cameron DJS, Catto-Smith AG: Increasing incidence of Crohn's disease in Victorian children. J Gastroenterol Hepatol 2003, 18:329-332. 
26. Parrello T, Pavia M: Angelillo IF, Monteleone G, Riegler G, Papi G, D'Inca R, Annese V, Tonelli F, Caprilli R. Pallone F: Appendectomy is an independent protective factor for ulcerative colitis: results of a multicentre case control study. The Italian Group for the Study of the Colon and Rectum (GISC) [see comment]. Ital J Gastroenterol 1997, 29:208-211.

27. Bernstein CN, Rawsthorne P, Blanchard JF: Population-based case-control study of measles, mumps, and rubella and inflammatory bowel disease. Inflamm Bowel Dis 2007, 13:759-762.

28. Jiang L, Xia B, Li J, Ye M, Deng C, Ding Y, Luo H, Ren H, Hou X, Liu H, et al: Risk factors for ulcerative colitis in a Chinese population: an age-matched and sex-matched case-control study. J Clin Gastroenterol 2007, 41:280-284.

29. Thompson NP, Fleming DM, Charlton J, Pounder RE, Wakefield AJ: Patients consulting with Crohn's disease in primary care in England and Wales. Eur J Gastroenterol Hepatol 1998, 10:1007-1012

30. Ruiz Ochoa V: [Epidemiologic study of Crohn's disease in Galicia from 1976 to 1983]. Rev Esp Enferm Apar Dig 1984, 66:273-279.

31. Sedlack RE, Whisnant J, Elveback LR, Kurland LT: Incidence of Crohn's disease in Olmsted County, Minnesota, 1935-1975. Am J Epidemiol 1980, 112:759-763.

32. Probert CS, Jayanthi V, Pinder D, Wicks AC, Mayberry JF: Epidemiological study of ulcerative proctocolitis in Indian migrants and the indigenous population of Leicestershire. Gut 1992, 33:687-693.

33. Niv $Y$, Torten D, Tamir A, Epstein $L$ : Incidence and prevalence of ulcerative colitis in the upper Galilee, Northern Israel, 1967-1986. American Journal of Gastroenterology 1990, 85:1580-1583.

34. Ladas S-D, Mallas E, Giorgiotis K, Karamanolis G, Trigonis D, Markadas A, Sipsa V, Raptis S-A: Incidence of ulcerative colitis in Central Greece: a prospective study. World Journal of Gastroenterology 2005, 11:1785-1787.

35. Wigley RD, Maclaurin BP: A study of ulcerative colitis in New Zealand, showing a low incidence in Maoris. British Medical Journal 1962, 2:228-231.

36. Shivananda S: Pena AS, Nap M, Weterman IT, Mayberry JF, Ruitenberg EJ. Hoedemaeker PJ: Epidemiology of Crohn's disease in Regio Leiden, The Netherlands. A population study from 1979 to 1983. Gastroenterology 1987, 93:966-974.

37. Rural/Urban Definition. Statistics UK. 2004. Retrieved Dec. 10, 2009 from Statistics. UK: http://www.statistics.gov.uk/geography/rudn.asp 2004.

38. du Plessis V, Beshiri R, Bollman R, Clemenson H: Definitions of "Rural". Agriculture and Rural Working Paper Series Working Paper No. 61. Ottawa, Ontario: Statistics Canada, Agriculture Division. http://www. statcan.ca/english/research/21-601-MIE/2002061/21-601-MIE2002061.pdf 2002, 37.

39. Mate-Jimenez J, Munoz S, Vicent D, Pajares JM: Incidence and prevalence of ulcerative colitis and Crohn's disease in urban and rural areas of Spain from 1981 to 1988. Journal of Clinical Gastroenterology 1994, 18:27-31.

40. Ekbom A, Helmick C, Zack M, Adami HO: The epidemiology of inflammatory bowel disease: a large, population-based study in Sweden. Gastroenterology 1991, 100:350-358.

41. Sincic BM, Vucelic B, Persic M, Brncic N, Erzen DJ, Radakovic B, Micovic V, Stimac D: Incidence of inflammatory bowel disease in Primorskogoranska County, Croatia, 2000-2004: A prospective population-based study.[see comment]. Scandinavian Journal of Gastroenterology 2006, 41:437-444.

42. Blanchard JF, Bernstein CN, Wajda A, Rawsthorne P: Small-area variations and sociodemographic correlates for the incidence of Crohn's disease and ulcerative colitis. American Journal of Epidemiology 2001, 154:328-335.

43. Lakatos L, Mester G, Erdelyi Z, Balogh M, Szipocs I, Kamaras G, Lakatos PL Epidemiology of inflammatory bowel diseases in Veszprem county of Western Hungary between 1977 and 2001. Orvosi Hetilap 2003, 144:1819-1827.

44. Manousos ON, Giannadaki E, Mouzas IA, Tzardi M, Koutroubakis I, Skordilis P, Vassilakis S, Kouroumalis E, Vlachonikolis IG: Ulcerative colitis is as common in Crete as in northern Europe: a 5-year prospective study. Eur J Gastroenterol Hepatol 1996, 8:893-898.

45. Latour P, Belaiche J, Louis E, Fontaine F, Deflandre J, Loly J, Oger A, Defrance $P, D i$ Valentin A, Delforge $M$, et al: Incidence of inflammatory bowel disease in the province of Liege (Belgium). La Societe de Gastroenterologie Liegeoise. Acta Gastroenterol Belg 1996, 59:3-6.

46. Martinez Salmeron JF, Rodrigo M, Nogueras F, de Sola C, Morales I, Martin-Vivaldi R: [The effect of environmental factors in inflammatory bowel disease]. Rev Esp Enferm Dig 1994, 86:642-644.
47. Kyle J: An epidemiological study of Crohn's disease in Northeast Scotland. Gastroenterology 1971, 61:826-833.

48. Jayanthi V, Probert CS, Pinder D, Wicks AC, Mayberry JF: Epidemiology of Crohn's disease in Indian migrants and the indigenous population in Leicestershire. Q J Med 1992, 82:125-138.

49. Kyle J: Crohn's disease in the northeastern and northern Isles of Scotland: an epidemiological review. [see comment]. Gastroenterology 1992, 103:392-399.

50. Moum B: Vatn MH, Ekbom A, Aadland E, Fausa O, Lygren I, Stray N, Sauar J. Schulz T:. Incidence of Crohn's disease in four counties in southeastern Norway, 1990-93. A prospective population-based study. The Inflammatory Bowel South-Eastern Norway (IBSEN) Study Group of Gastroenterologists. Scandinavian Journal of Gastroenterology 1996, 31:355-361.

51. Nyhlin H, Danielsson A: Incidence of Crohn's disease in a defined population in northern Sweden, 1974-1981. Scandinavian Journal of Gastroenterology 1986, 21:1185-1192.

52. Brandes JW, Lorenz-Meyer $\mathrm{H}$ : Epidemiologic aspects of Crohn regional enterocolitis and ulcerative colitis in Marburg/Lahn (West Germany) between 1962 and 1975. Zeitschrift fur Gastroenterologie 1983, 21:69-78

53. Ponsonby A-L, Catto-Smith AG, Pezic A, Dupuis S, Halliday J, Cameron D, Morley R, Carlin J, Dwyer T: Association between early-life factors and risk of child-onset Crohn's disease among victorian children born 1983-1998: a birth cohort study. Inflamm Bowel Dis 2009, 15:858-866.

54. Radon K, Windstetter D, Poluda AL, Mueller B, von Mutius E, Koletzko S: Chronische Autoimmunerkrankungen und Kontakt zu Tieren Study G: Contact with farm animals in early life and juvenile inflammatory bowel disease: a case-control study. Pediatrics 2007, 120:354-361.

55. Shanahan F, Bernstein CN: The evolving epidemiology of inflammatory bowel disease. Current Opinion in Gastroenterology 2009, 25:301-305.

56. Gent AE, Hellier MD, Grace RH, Swarbrick ET, Coggon D: Inflammatory bowel disease and domestic hygiene in infancy. [see comment]. Lancet 1994, 343:766-767.

57. Korzenik JR: Past and current theories of etiology of IBD: toothpaste, worms, and refrigerators. Journal of Clinical Gastroenterology 2005, 39:S59-65.

58. Calkins BM: A meta-analysis of the role of smoking in inflammatory bowel disease. Dig Dis Sci 1989, 34:1841-1854.

59. Card T, Logan RFA, Rodrigues LC, Wheeler JG: Antibiotic use and the development of Crohn's disease. [see comment]. Gut 2004, 53:246-250.

60. Kaplan GG, Hubbard J, Korzenik J, Sands BE, Panaccione R, Ghosh S, Wheeler AJ, Villeneuve PJ: The inflammatory bowel diseases and ambient air pollution: a novel association. Am J Gastroenterol 2010, 105:2412-2419.

61. Li $X$, Sundquist J, Sundquist K: Educational level and occupation as risk factors for inflammatory bowel diseases: A nationwide study based on hospitalizations in Sweden. Inflamm Bowel Dis 2009, 15:608-615.

62. Loftus EV Jr: Clinical epidemiology of inflammatory bowel disease: Incidence, prevalence, and environmental influences. Gastroenterology 2004, 126:1504-1517

63. Gaya DR, Russell RK, Nimmo ER, Satsangi J: New genes in inflammatory bowel disease: lessons for complex diseases? Lancet 2006, 367:1271-1284.

doi:10.1186/1471-230X-12-51

Cite this article as: Soon et al:: The relationship between urban environment and the inflammatory bowel diseases: a systematic review and meta-analysis. BMC Gastroenterology 2012 12:51.

\section{Submit your next manuscript to BioMed Central and take full advantage of:}

- Convenient online submission

- Thorough peer review

- No space constraints or color figure charges

- Immediate publication on acceptance

- Inclusion in PubMed, CAS, Scopus and Google Scholar

- Research which is freely available for redistribution 